\title{
Factors Influencing Changes in Hemoglobin A1c and Body Weight During Treatment of Type 2 Diabetes With Ipragliflozin: Interim Analysis of the ASSIGN-K Study
}

\author{
Kotaro Iemitsu ${ }^{\mathrm{a}}$, Takashi Iizuka ${ }^{\mathrm{a}}$, Masahiro Takihata ${ }^{\mathrm{a}}$, Masahiko Takai ${ }^{\mathrm{a}}$, Shigeru Nakajima ${ }^{\mathrm{a}}$, \\ Nobuaki Minami ${ }^{\mathrm{a}}$, Shinichi Umezawa ${ }^{\mathrm{a}}$, Akira Kanamori ${ }^{\mathrm{a}}$, Hiroshi Takeda ${ }^{\mathrm{a}}$, Takehiro Kawata ${ }^{\mathrm{a}}$, \\ Shogo Ito ${ }^{a}$, Taisuke Kikuchi ${ }^{\mathrm{a}}$, Hikaru Amemiya ${ }^{\mathrm{a}}$, Mizuki Kaneshiro ${ }^{\mathrm{a}}$, Atsuko Mokubo ${ }^{\mathrm{a}}$, Tetsuro Takuma ${ }^{\mathrm{a}}$, \\ Hideo Machimura ${ }^{a}$, Keiji Tanaka ${ }^{a}$, Taro Asakura ${ }^{a}$, Akira Kubota ${ }^{a}$, Sachio Aoyagia ${ }^{a}$ Kazuhiko Hoshino ${ }^{a}$, \\ Masashi Ishikawa ${ }^{\mathrm{a}}$, Mitsuo Obana ${ }^{\mathrm{a}}$, Nobuo Sasai ${ }^{\mathrm{a}}$, Hideaki Kaneshige ${ }^{\mathrm{a}}$, Masaaki Miyakawa ${ }^{\mathrm{a}}$, \\ Yasushi Tanaka ${ }^{\mathrm{a}, \mathrm{b}}$, Yasuo Terauchic ${ }^{\mathrm{c}}$, Ikuro Matsuba ${ }^{\mathrm{a}, \mathrm{d}}$
}

\begin{abstract}
Background: Ipragliflozin is a selective sodium glucose co-transporter 2 (SGLT2) inhibitor that blocks glucose reabsorption in the proximal tubules. SGLT2 inhibitors are expected to be effective in patients with insulin resistance and obesity, but it is important to select treatment according to patient background factors that minimizes the risk of adverse events. There have been a limited number of investigations into the relationship between the clinical efficacy (reducing hemoglobin A1c (HbA1c) and body weight (BW)) or safety of SGLT2 inhibitors and patient characteristics.
\end{abstract}

Methods: ASSIGN-K is an investigator-initiated, multicenter, prospective observational study examining the efficacy and safety of ipragliflozin (50 - $100 \mathrm{mg}$ /day for 52 weeks) in Japanese patients with type 2 diabetes mellitus (T2DM) who had inadequate glycemic control with $\mathrm{HbAlc} \geq 6.0 \%$ (National Glycohemoglobin Standardization Program) despite diet and exercise therapy or diet and exercise plus antidiabetic drug therapy. We conducted an interim analysis of the relationship between changes in $\mathrm{HbA} 1 \mathrm{c}$ or BW and characteristics in patients who had been on treatment for more than 12 weeks.

Results: In 257 patients completing 12 weeks of treatment, HbA1c decreased significantly from $8.23 \%$ to $7.55 \%(-0.68 \%, \mathrm{P}<0.01)$. The change in $\mathrm{HbA} 1 \mathrm{c}$ after 12 weeks was $-0.17 \%,-0.33 \%$, and $-1.16 \%$ when baseline $\mathrm{HbA} 1 \mathrm{c}$ was $<7 \%, 7 \%$ to $<8 \%$, and $\geq 8 \%$, respectively

Manuscript accepted for publication February 15, 2016

aStudy Group of the Diabetes Committee, Kanagawa Physicians Association, Kanagawa, Japan

bDivision of Metabolism and Endocrinology, Department of Internal Medicine, St. Marianna University School of Medicine, Kanagawa, Japan 'Department of Endocrinology and Diabetes, Yokohama City University Medical Center, Kanagawa, Japan

${ }^{\mathrm{d} C}$ Corresponding Author: Ikuro Matsuba, Matsuba Clinic, 2-159 Tsukagoshi, Saiwai-ku, Kawasaki-shi, Kanagawa 212-0024, Japan.

Email: ikuro@matsuba-web.com

doi: http://dx.doi.org/10.14740/jocmr2492w
( $\mathrm{P}<0.05, \mathrm{P}<0.01$, and $\mathrm{P}<0.01$, respectively), and $-1.30 \%,-0.62 \%$, and $-0.62 \%$ when baseline body mass index (BMI) was $<25,25$ to $<$ 30 , and $\geq 30$, respectively (all $\mathrm{P}<0.01$ ). Stratified analysis showed that age, gender, or BMI did not have a significant influence on the improvement in $\mathrm{HbA1c}$. Multiple regression analysis showed that reduction in $\mathrm{HbAlc}$ was greater as baseline $\mathrm{HbAlc}$ increased and the duration of diabetes decreased. A higher baseline $\mathrm{HbAlc}$ was associated with less weight loss.

Conclusions: Ipragliflozin significantly improved $\mathrm{HbAlc}$ in patients with T2DM. HbA1c improved more when baseline HbA1c was higher and the duration of diabetes was shorter, suggesting that current treatment policies for diabetes could be re-examined.

Keywords: Type 2 diabetes; Ipragliflozin; Selective sodium glucose co-transporter 2 inhibitor; Hemoglobin A1c; Body weight; Patient characteristics; Interim analysis

\section{Introduction}

After being absorbed from the intestinal tract, glucose is filtered through the glomeruli of the kidneys and then reabsorbed in the proximal tubules. Sodium glucose co-transporter 2 (SGLT2) has the main role in glucose reabsorption $[1,2]$. SGLT2 inhibitors can be used to treat diabetes without acting on insulin secretion through reduction in the blood glucose level by inhibiting glucose reabsorption in the proximal tubules. In Japanese clinical studies of various SGLT2 inhibitors, improvement in glycemic control has been clearly demonstrated [3-9], and a number of these drugs have been approved in Japan since 2014. Because the mechanism of action of SGLT2 inhibitors does not depend on insulin secretion, these agents can be administered concurrently with antidiabetic drugs of other classes and have been demonstrated to reduce body weight (BW) and lower blood pressure [10]. SGLT2 inhibitors are listed as an option for combined therapy in the 2015 treatment algorithms of the EU and the USA [11]. While urinary 


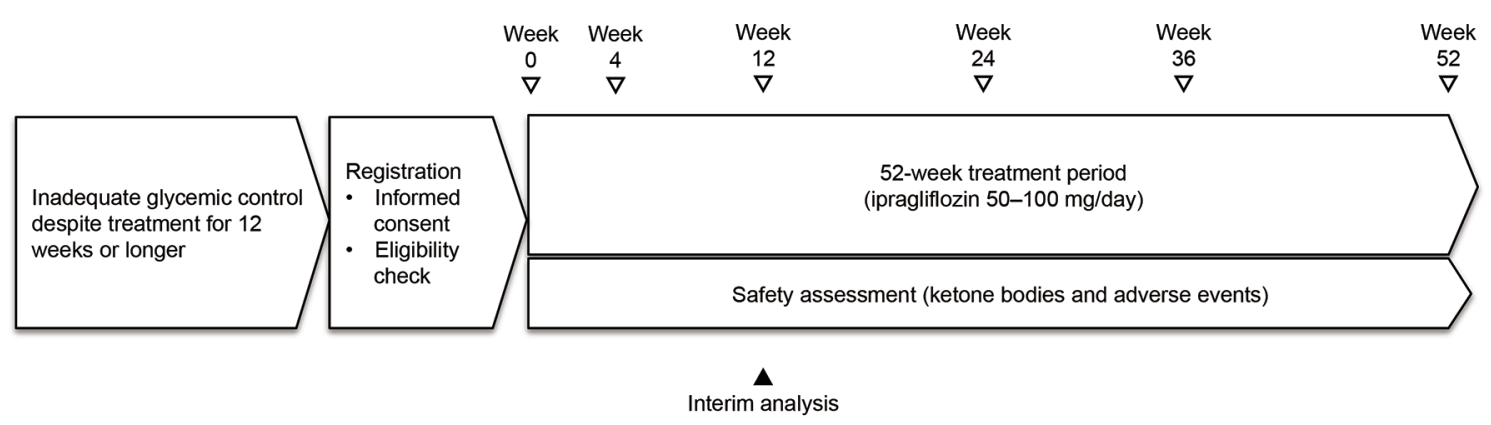

Figure 1. Outline of the study.

tract and genital tract infections are characteristic side effects of SGLT2 inhibitors reported in clinical trials, serious adverse drug reactions such as severe hypoglycemia, ketoacidosis, or generalized skin rash have been reported in patients using insulin products and sulfonylureas in the real clinical setting.

In patients taking SGLT2 inhibitors, osmotic diuresis associated with increased urinary excretion of glucose has been reported to cause dehydration, which has been suggested to be a possible cause of cerebral infarction. Accordingly, the Committee on the Proper Use of SGLT2 Inhibitors of the Japanese Diabetes Society formulated recommendations for proper use of SGLT2 inhibitors in 2014, which listed precautions regarding dehydration, urinary tract infection, and genital tract infection when administering SGLT2 inhibitors concurrently with insulin or sulfonylureas in elderly patients.

SGLT2 inhibitors are expected to be effective in patients with insulin resistance and obesity since these drugs promote weight loss and do not rely on insulin to reduce glucose levels, but it is important to select treatment according to patient background factors that minimizes the risk of adverse events (AEs). However, there have been a limited number of investigations into the relationship between the clinical efficacy (reducing hemoglobin A1c (HbA1c) and BW) or safety of SGLT2 inhibitors and patient characteristics.

In a phase II trial of the selective SGLT2 inhibitor ipragliflozin in Japanese patients with type 2 diabetes mellitus (T2DM) [3], HbA1c was reduced by $0.81 \%$ and BW was decreased by $2.1 \mathrm{~kg}$ after 12 weeks of treatment at $100 \mathrm{mg} /$ day. When stratified analysis was performed to compare patients with lower baseline HbA1c levels $(<8.4 \%)$ and higher baseline HbA1c levels $(\geq 8.4 \%)$, the change in HbA1c was significantly larger in the latter group $(\mathrm{P}<0.001)$. On the other hand, there was no significant difference in the change in $\mathrm{HbA} 1 \mathrm{c}$ between patients with and without prior drug therapy $(\mathrm{P}=0.106)$ or between obese and non-obese subjects $(P=0.228)$. In other trials of ipragliflozin, the change in $\mathrm{HbAlc}$ has tended to be larger in patients with higher baseline HbA1c levels [4, 12-14].

We have been conducting the ASSIGN-K study, which is an investigator-initiated, multicenter, prospective study designed to examine the efficacy and safety of ipragliflozin in real-world clinical practice, either as monotherapy after switching from other antidiabetic agents or combined with existing therapy. The efficacy of ipragliflozin for glycemic control and its safety have already been reported [15]. In the present study, we performed an interim analysis of the influence of patient characteristics on changes in $\mathrm{HbA} 1 \mathrm{c}$ and $\mathrm{BW}$ during treatment with ipragliflozin.

\section{Patients and Methods}

\section{Study design}

ASSIGN-K is an investigator-initiated, multicenter, prospective study that is investigating the efficacy and safety of ipragliflozin in routine clinical practice, either as monotherapy after switching from previous antidiabetic agents or when added to existing treatment [15]. Thirty-three hospitals in Kanagawa Prefecture participated in the study, which started in June 2014, and registration was completed in May 2015. All patients gave written informed consent to participation. The study complied with the Declaration of Helsinki and the protocol and consent/ explanatory material were approved by an appropriate institutional review board before the study started (June 17, 2014).

\section{Subjects}

The subjects were Japanese patients with T2DM who were at least 20 years old at the time of giving informed consent and had inadequate glycemic control with $\mathrm{HbA} 1 \mathrm{c} \geq 6.0 \%$ (National Glycohemoglobin Standardization Program) despite diet and exercise therapy or diet and exercise plus antidiabetic drug therapy for at least 12 weeks.

The exclusion criteria were as follows: 1) a history of hypersensitivity to ipragliflozin, 2) a history of severe ketotic diabetic coma or comatose state within the past 6 months, 3) severe infection, preoperative/postoperative state, or severe trauma, 4) severe renal dysfunction, 5) women who were pregnant, possibly pregnant, planning to become pregnant during the study period, or breast-feeding, and 6) other patients who were considered to be ineligible by the investigator or subinvestigator.

\section{Study treatment}

Subjects were administered ipragliflozin at a dose of 50 or 100 $\mathrm{mg}$ orally once a day before or after breakfast for 52 weeks 
Table 1. Characteristics of the Patients

\begin{tabular}{|c|c|}
\hline \multicolumn{2}{|l|}{ Characteristics } \\
\hline Number & 257 \\
\hline Age, mean $\pm \mathrm{SD}$ & $53.9 \pm 10.4$ \\
\hline$<65$ years, $\mathrm{n}(\%)$ & $215(83.7)$ \\
\hline$\geq 65$ years, $\mathrm{n}(\%)$ & $42(16.3)$ \\
\hline \multicolumn{2}{|l|}{ Sex } \\
\hline Male, n (\%) & $123(47.9)$ \\
\hline Female, n (\%) & $134(52.1)$ \\
\hline Weight, $\mathrm{kg}$, mean $\pm \mathrm{SD}$ & $80.3 \pm 17.4$ \\
\hline $\mathrm{BMI}, \mathrm{kg} / \mathrm{m}^{2}$, mean $\pm \mathrm{SD}$ & $30.0 \pm 5.4$ \\
\hline $\mathrm{HbAlc}, \%(\mathrm{NGSP})$, mean $\pm \mathrm{SD}(\mathrm{n})$ & $8.2 \pm 1.5(254)$ \\
\hline Fasting glucose, mg/dL, mean \pm SD (n) & $158.5 \pm 43.6(110)$ \\
\hline Postprandial glucose, mg/dL, mean \pm SD (n) & $199.1 \pm 85.2(93)$ \\
\hline Duration of diabetes, years, mean $\pm \mathrm{SD}(\mathrm{n})$ & $9.6 \pm 6.9(248)$ \\
\hline Systolic blood pressure, mm Hg, mean \pm SD (n) & $131.3 \pm 15.9(254)$ \\
\hline Diastolic blood pressure, $\mathrm{mm} \mathrm{Hg}$, mean $\pm \mathrm{SD}(\mathrm{n})$ & $78.3 \pm 10.6(254)$ \\
\hline $\mathrm{eGFR}, \mathrm{mL} / \mathrm{min} / 1.73 \mathrm{~m}^{2}$, mean $\pm \mathrm{SD}$ & $83.89 \pm 21.67$ \\
\hline$<60 \mathrm{~mL} / \mathrm{min} / 1.73 \mathrm{~m}^{2}, \mathrm{n}(\%)$ & $31(12.3)$ \\
\hline$\geq 60 \mathrm{~mL} / \mathrm{min} / 1.73 \mathrm{~m}^{2}, \mathrm{n}(\%)$ & $222(87.7)$ \\
\hline \multicolumn{2}{|l|}{ Drinking alcohol } \\
\hline Yes, number $(\%)$ & $87(33.9)$ \\
\hline No, number $(\%)$ & $169(65.8)$ \\
\hline \multicolumn{2}{|l|}{ Smoking tobacco } \\
\hline Yes, number $(\%)$ & $78(30.4)$ \\
\hline No, number (\%) & $178(69.3)$ \\
\hline
\end{tabular}

SD: standard deviation; BMI: body mass index; HbA1c: hemoglobin A1c; NGSP: National Glycohemoglobin Standardization Program; eGFR: estimated glomerular filtration rate.

(Fig. 1). Concomitant administration of other SGLT2 inhibitors was prohibited. In addition, diet therapy, exercise therapy, or specified health foods could not be started, discontinued, or altered during the study period. Furthermore, medications such as antiplatelet agents, antihypertensive drugs, and lipidlowering agents were not changed in dose, discontinued, or newly added if possible.

\section{Endpoints}

The primary efficacy endpoint of this study was the change in HbA1c after 52 weeks of treatment. The secondary efficacy endpoints were the changes after initiation of treatment in the fasting blood glucose level, postprandial blood glucose level, body composition, BW, waist circumference, serum lipids, free fatty acids, and blood pressure, as well as the improvement in $\mathrm{HbA}$ lc stratified by patient characteristics at the initiation of treatment. All efficacy endpoints were evaluated in week 4, week 12 , week 24 , week 36 , and week 52 . Safety endpoints were the change in blood ketone bodies after initiation of treat-
Table 2. Changes in Parameters Related to Glycemic Control and Body Weight

\begin{tabular}{lllll}
\hline & n & Baseline & Week 4 & Week 12 \\
\hline HbA1c, \% & 257 & 8.23 & $7.81^{*}$ & $7.55^{* \dagger}$ \\
Fasting glucose, mg/dL & 110 & 158.5 & $139.2^{*}$ & $134.6^{*}$ \\
Postprandial glucose, mg/dL & 93 & 199.1 & $161.0^{*}$ & $154.9^{*}$ \\
Body weight, kg & 240 & 79.9 & $78.8^{*}$ & $78.1^{* \dagger}$ \\
BMI, kg/m ${ }^{2}$ & 241 & 29.9 & $29.5^{*}$ & $29.2^{* \dagger}$ \\
Waist circumference, cm & 250 & 101.2 & $99.9^{*}$ & $99.0^{* \dagger}$ \\
\hline
\end{tabular}

Analysis of variance: vs. baseline ${ }^{*} \mathrm{P}<0.01$, week 4 vs. week $12 \nmid P<$ 0.01 . HbA1c: hemoglobin A1c; BMl: body mass index.

ment, as well as AEs and adverse reactions.

The present interim analysis was performed in patients who had been on treatment for more than 12 weeks as of December 25, 2014 (Table 1), and the details were reported previously [15]. The present report describes patient characteristics influencing the changes in $\mathrm{HbA1c}$ and BW up to week 12.

\section{Statistical analysis}

Summary statistics were calculated or the frequency was determined for patient characteristics, efficacy endpoints, and changes from baseline. Analysis of variance was used for stratified analysis of the change in each endpoint from baseline to week 12 and the change in HbAlc. Patient characteristics that influenced the changes in $\mathrm{HbAlc}$ and $\mathrm{BW}$ were investigated by stepwise multiple regression analysis using a significance level of $\mathrm{P}<0.05$.

For safety assessment, the frequency of AEs and the percentage of patients affected were determined. Medical Dictionary for Regulatory Activities (MedDRA) Preferred Terms were used for coding AEs, and System Organ Class names were used to describe the affected organs. Any AE for which a causal relationship with ipragliflozin could not be ruled out was classified as an adverse reaction.

\section{Results}

\section{Patient characteristics}

At the interim analysis, 257 patients were available for analysis of efficacy and 301 patients were available for assessment of safety. Table 1 shows the characteristics of the patients included in the interim efficacy analysis. Their mean age was 53.9 years and $83.7 \%$ were younger than 65 years. The male to female ratio was approximately $1: 1$, and the mean baseline HbAlc was $8.2 \%$.

Of the 257 patients, 28 (10.9\%) switched to ipragliflozin from other antidiabetic agents, including thiazolidinediones in 10 patients, sulfonylureas in eight patients, dipeptidyl peptidase 4 inhibitors in six patients, biguanides in four patients, insulin products in three patients, and alpha glucosidase in- 
Table 3. Multiple Regression Analysis of Factors Influencing the Change in $\mathrm{HbA} 1 \mathrm{c}$ in Week 12

\begin{tabular}{llll}
$\begin{array}{l}\text { Independent } \\
\text { variable }\end{array}$ & $\begin{array}{l}\text { Standardized } \\
\text { coefficient } \boldsymbol{\beta}\end{array}$ & $\begin{array}{l}\text { Partial regression } \\
\text { coefficient }\end{array}$ & P value \\
\hline Constant & 0 & 2.050 & 0.0034 \\
Age & 0.020 & 0.002 & 0.7324 \\
Sex & 0.081 & 0.203 & 0.1196 \\
Duration of diabetes & 0.205 & 0.037 & 0.0003 \\
BMI (baseline) & 0.080 & 0.019 & 0.1213 \\
HbA1c (baseline) & -0.585 & -0.485 & $<0.0001$ \\
Switching treatment & 0.206 & 0.806 & $<0.0001$ \\
\hline
\end{tabular}

$n=243$. Stepwise analysis with the following independent variables: age, sex, duration of diabetes, baseline $\mathrm{HbA1c}$, baseline $\mathrm{BMI}$, and treatment category (new monotherapy, concurrent administration, or switching treatment). Dependent variable: decrease in $\mathrm{HbA1c}$. BMl: body mass index; HbA1c: hemoglobin A1c.

hibitors in two patients. Details of the concomitant drugs were described previously [15].

\section{Changes in HbA1c, blood glucose, and BW}

Mean HbA1c showed a decrease of $0.68 \%$ (from $8.23 \%$ to $7.55 \%$ ) between initiation of treatment and week 12 , which was a significant improvement $(\mathrm{P}<0.01)$. The fasting blood glucose level and postprandial blood glucose level decreased by $23.9 \mathrm{mg} / \mathrm{dL}$ (from 158.5 to $134.6 \mathrm{mg} / \mathrm{dL}$ ) and $44.2 \mathrm{mg} / \mathrm{dL}$ (from 199.1 to $154.9 \mathrm{mg} / \mathrm{dL}$ ), respectively, also showing significant improvement (both $\mathrm{P}<0.01$ ). Furthermore, the BW, body mass index (BMI), and waist circumference were significantly reduced from 79.9 to $78.1 \mathrm{~kg}, 29.9$ to $29.2 \mathrm{~kg} / \mathrm{m}^{2}$, and 101.2 to $99.0 \mathrm{~cm}$, respectively (all $\mathrm{P}<0.01$, Table 2 ).

\section{Influence of patient characteristics on the change in HbA1c}

Stratified analysis was carried out to determine the influence of age, sex, duration of diabetes, BMI, estimated glomerular filtration rate (eGFR), and HbAlc at the start of treatment on the change in $\mathrm{HbAlc}$ in week 12 of treatment. Age did not have a significant influence on the improvement in $\mathrm{HbA} 1 \mathrm{c}$ because the mean change was $-0.73 \%$ in patients $<65$ years (n $=208)$ and $-0.59 \%$ in those aged $\geq 65$ years $(n=43)$ (both $\mathrm{P}<$ 0.01 ). Gender also had no significant influence on the improvement in $\mathrm{HbA} 1 \mathrm{c}$, with the mean change in $\mathrm{HbA} 1 \mathrm{c}$ being $-0.83 \%$ in male patients $(\mathrm{n}=120)$ and $-0.63 \%$ in female patients $(\mathrm{n}$ $=129$ ). Furthermore, BMI was not a significant influence on HbAlc since the mean change in HbA1c in patients with a baseline BMI $\left(\mathrm{kg} / \mathrm{m}^{2}\right)$ of $<25(\mathrm{n}=33), 25$ to $<30(\mathrm{n}=114)$, and $\geq 30(\mathrm{n}=102)$ was $-1.30 \%,-0.62 \%$, and $-0.62 \%$, respectively (all $\mathrm{P}<0.01$ ). In contrast, baseline HbA1c significantly influenced the improvement in HbAlc after 12 weeks of ipragliflozin treatment, and the mean change in $\mathrm{HbA} 1 \mathrm{c}$ in patients with a baseline $\mathrm{HbA1c}<7 \%(\mathrm{n}=46), 7 \%$ to $<8 \%(\mathrm{n}=64)$, or $\geq 8 \%(\mathrm{n}=126)$ was $-0.17 \%,-0.33 \%$, and $-1.16 \%$, respectively
Table 4. Multiple Regression Analysis of Factors Influencing the Change in Body Weight in Week 12

\begin{tabular}{llll}
\hline $\begin{array}{l}\text { Independent } \\
\text { variable }\end{array}$ & $\begin{array}{l}\text { Standardized } \\
\text { coefficient } \boldsymbol{\beta}\end{array}$ & $\begin{array}{l}\text { Partial regression } \\
\text { coefficient }\end{array}$ & $\begin{array}{l}\mathbf{P} \\
\text { value }\end{array}$ \\
\hline Constant & 0 & -0.117 & 0.9422 \\
Age & -0.065 & -0.015 & 0.3714 \\
Sex & -0.092 & -0.436 & 0.1447 \\
\hline Duration of diabetes & 0.051 & 0.018 & 0.4502 \\
\hline BMI (baseline) & -0.237 & -0.111 & 0.0002 \\
\hline HbA1c (baseline) & 0.215 & 0.334 & 0.0005 \\
\hline
\end{tabular}

$n=238$. Stepwise analysis with the following independent variables: age, sex, duration of diabetes, baseline $\mathrm{HbA} 1 \mathrm{c}$, and baseline BMI. Dependent variable: decrease in body weight. BMI: body mass index; $\mathrm{HbA1c}$ : hemoglobin A1c.

$(\mathrm{P}<0.05, \mathrm{P}<0.01$, and $\mathrm{P}<0.01$, respectively $)$.

\section{Multiple regression analysis of factors influencing changes in $\mathrm{HbA1c}$ and $\mathrm{BW}$}

Stepwise multiple regression analysis was carried out using the change in $\mathrm{HbA} 1 \mathrm{c}$ from baseline in week 12 of treatment as the dependent variable and the age, sex, duration of diabetes, HbA1c, BMI, and medications at the initiation of treatment as independent variables (Tables 3, 4). Regarding the influence on $\mathrm{HbA} 1 \mathrm{c}$ in week 12, the standardized coefficient beta for baseline $\mathrm{HbA} 1 \mathrm{c}$ and disease duration was -0.585 and 0.205 , respectively, demonstrating that a higher baseline $\mathrm{HbA} 1 \mathrm{c}$ and shorter disease duration were associated with greater reduction in $\operatorname{HbA1c}(\mathrm{P}<0.0001$ and $\mathrm{P}=0.0003$, respectively). HbAlc was significantly more likely to increase in patients who switched antidiabetic drugs at initiation of treatment $(\mathrm{P}$ $<0.0001)$. On the other hand, baseline BMI did not have a significant influence on the change in $\operatorname{HbA1c}(\mathrm{P}=0.1213)$. Regarding the influence on $\mathrm{BW}$ in week 12, the standardized coefficient beta for baseline HbA1c and BMI was 0.215 and -0.237 , respectively, demonstrating that weight loss was smaller as baseline HbAlc became higher, while a higher baseline BMI was associated with greater weight loss $(\mathrm{P}=0.0005$ and $\mathrm{P}=0.0002$, respectively).

\section{Safety}

Detailed safety data were reported previously [15]. Of the 301 patients who were included in the analysis of safety, 68 $(22.6 \%)$ had AEs. The most frequent AE was vulvovaginal candidiasis, which was reported in eight patients $(2.7 \%)$, followed by cystitis in six patients $(2.0 \%)$, genital pruritus in five patients $(1.7 \%)$, eczema and nasopharyngitis in four patients each $(1.3 \%)$, and drug eruption, nausea, and constipation in three patients each $(1.0 \%)$.

Three serious AEs occurred, including ketosis, unstable angina, and urinary tract infection. Ketosis occurred in a patient who did not suspend medication after developing vomit- 
ing and diarrhea.

\section{Discussion}

The main feature of the ASSIGN-K study is that evaluation of ipragliflozin is being conducted in real-world clinical practice, allowing us to verify whether results obtained in the routine clinical setting are consistent with those of previous Japanese clinical studies. We found that the mean decrease in HbAlc from baseline to week 12 of treatment was $0.68 \%$ [15]. Significant improvement in $\mathrm{HbAlc}$ was noted throughout the assessment period, with a decrease of $0.43 \%$ by week 4 after initiation of treatment and further significant reduction from week 4 to week $12(0.68 \%)$. A similar time-dependent effect of ipragliflozin on HbA1c was also observed up to week 12 in the phase II dose-finding trial [3].

It is thought that improvement in HbAlc by week 4 in the present study was related to increased urinary glucose excretion, while the further decrease in HbA1c in week 12 was due to improvement in insulin resistance associated with reduced glucose toxicity or weight loss. A phase II study conducted outside Japan identified a correlation between weight loss and improvement in insulin sensitivity [16]. In the present study, there was significant weight loss of $1.8 \mathrm{~kg}$ by week $12(\mathrm{P}<$ 0.01 ) and there was also a difference of BW between week 4 and week 12. As we reported previously [15], early weight loss by week 4 may be largely related to fluid loss because of osmotic diuresis associated with increased urinary glucose excretion, while ongoing weight loss until week 12 may represent reduction in body fat. In Japan, it has been reported that approximately $50 \%$ of weight loss associated with ipragliflozin therapy is due to body fat reduction and approximately $20 \%$ is from the decrease in extracellular fluid [17].

Our stratified analysis confirmed that significant improvement in HbA1c occurred by week 12 of ipragliflozin treatment regardless of age, sex, duration of diabetes, baseline BMI, baseline eGFR, or baseline HbAlc. However, there was a correlation between baseline $\mathrm{HbA} 1 \mathrm{c}$ or the duration of diabetes and the change in HbA1c by week 12 . That is, the decrease in $\mathrm{HbA1c}$ was larger in patients with a higher baseline HbA1c, presumably because the effect of SGLT2 inhibitors on urinary glucose excretion is stronger when HbAlc is higher. In the phase II clinical study of ipragliflozin performed in Japanese patients with T2DM [2], a higher baseline HbA1c was also associated with a better response of $\mathrm{HbA} 1 \mathrm{c}$ to treatment. In addition, we found that the improvement in $\mathrm{HbA} 1 \mathrm{c}$ was larger as the duration of diabetes became shorter. The efficacy of SGLT2 inhibitors may be reduced in patients with a longer disease duration owing to upregulation of SGLT2 expression or elevation of the renal glucose threshold, which would reduce urinary glucose excretion, and there may be less response of endogenous insulin secretion to the reduction of glucose toxicity. We confirmed that the baseline BMI had no influence on the change in $\mathrm{HbA} 1 \mathrm{c}$ with ipragliflozin treatment.

Analysis of factors influencing BW showed that weight loss increased as baseline BMI became higher, while the reduction in BW became smaller as the baseline HbA1c increased.
Of the 257 patients in this study, 47 patients were also using insulin and their mean $\mathrm{HbA} 1 \mathrm{c}$ was $8.9 \%$ at the start of treatment, whereas the patients who did not use insulin had a baseline HbA1c of $8.1 \%$. The number of patients who lost weight in the insulin subgroup was $10(21.3 \%)$ versus $28(13.3 \%)$ in the non-insulin subgroup, suggesting that there may be less weight loss with concomitant insulin administration.

The main AEs identified during this study included urinary tract and genital tract infections, respiratory tract infections, and skin conditions, which were similar to the AEs reported in Japanese clinical studies of other SGLT2 inhibitors [3-9]. Three serious AEs were observed, including ketosis, unstable angina, and urinary tract infection. Ketosis occurred in a patient who did not suspend treatment when vomiting and diarrhea occurred, emphasizing the importance of patient education about handling acute illness. As patients with a higher baseline HbA1c had increased urinary glucose excretion, osmotic diuresis may be greater during the early treatment period, and such patients should be encouraged to maintain sufficient water intake.

\section{Conclusion}

In the present interim analysis of the ASSIGN-K study, clinical characteristics influencing the changes in $\mathrm{HbA} 1 \mathrm{c}$ and $\mathrm{BW}$ after 12 weeks of ipragliflozin treatment were investigated. HbA1c and BW both showed a significant decrease after 4 weeks of treatment and there was a further significant reduction from week 4 to week 12 . This study revealed that there was greater improvement in HbA1c with ipragliflozin treatment as baseline $\mathrm{HbA} 1 \mathrm{c}$ increased and the disease duration became shorter, while baseline BMI did not influence the change in HbAlc. Regarding BW, it was demonstrated that a higher baseline BMI was associated with larger weight loss, while a higher baseline HbA1c was associated with smaller weight loss. This study confirmed that the short-term efficacy and safety of ipragliflozin were consistent with findings obtained in previous Japanese clinical studies. It seems that SGLT2 inhibitors can reduce $\mathrm{HbA} 1 \mathrm{c}$ in patients with a higher baseline $\mathrm{HbA1c}$ and shorter duration of diabetes irrespective of baseline BMI, which suggests that current treatment policies for diabetes could be re-examined.

\section{Acknowledgement}

ASSIGN-K is a prospective study of the Kanagawa Physicians Association that is currently in progress. We would like to thank the physicians and staff of the Kanagawa Physicians Association involved in the research and the patients participating in this study.

\section{Disclosure}

The authors declare that there is no conflict of interest regarding the publication of this paper. This research was planned 
by the Study Group of the Diabetes Committee of Kanagawa Physicians Association and was financially supported by Astellas Pharma, Inc. The company was not involved in the study design, patient enrollment, data aggregation and analysis, data interpretation, or preparation of this report.

\section{References}

1. Kanai Y, Lee WS, You G, Brown D, Hediger MA. The human kidney low affinity $\mathrm{Na}+$ /glucose cotransporter SGLT2. Delineation of the major renal reabsorptive mechanism for D-glucose. J Clin Invest. 1994;93(1):397404.

2. Wright EM, Hirayama BA, Loo DF. Active sugar transport in health and disease. J Intern Med. 2007;261(1):3243.

3. Kashiwagi A, Kazuta K, Yoshida S, Nagase I. Randomized, placebo-controlled, double-blind glycemic control trial of novel sodium-dependent glucose cotransporter 2 inhibitor ipragliflozin in Japanese patients with type 2 diabetes mellitus. J Diabetes Investig. 2014;5(4):382391.

4. Kashiwagi A, Kawano H, Kazuta K. Long-term safety, tolerability and efficacy of ipragliflozin in Japanese patients with type 2 diabetes mellitus-IGNITE Study. Jpn Pharmacol Ther. 2015;43(1):85-100.

5. Seino Y, Sasaki T, Fukatsu A, Ubukata M, Sakai S, Samukawa Y. Efficacy and safety of luseogliflozin as monotherapy in Japanese patients with type 2 diabetes mellitus: a randomized, double-blind, placebo-controlled, phase 3 study. Curr Med Res Opin. 2014;30(7):1245-1255.

6. Kaku K, Watada H, Iwamoto Y, Utsunomiya K, Terauchi Y, Tobe K, Tanizawa Y, et al. Efficacy and safety of monotherapy with the novel sodium/glucose cotransporter-2 inhibitor tofogliflozin in Japanese patients with type 2 diabetes mellitus: a combined Phase 2 and 3 randomized, placebo-controlled, double-blind, parallel-group comparative study. Cardiovasc Diabetol. 2014;13:65.

7. Inagaki N, Kondo K, Yoshinari T, Kuki H. Efficacy and safety of canagliflozin alone or as add-on to other oral antihyperglycemic drugs in Japanese patients with type 2 diabetes: A 52-week open-label study. J Diabetes Investig. 2015;6(2):210-218.

8. Kaku K, Maegawa H, Tanizawa Y, Kiyosue A, Ide Y, Tokudome T, Hoshino Y, et al. Dapagliflozin as monotherapy or combination therapy in Japanese patients with type 2 diabetes: an open-label study. Diabetes Ther. 2014;5(2):415-433.
9. Kadowaki T, Haneda M, Inagaki N, Terauchi Y, Taniguchi A, Koiwai K, Rattunde H, et al. Efficacy and safety of empagliflozin monotherapy for 52 weeks in Japanese patients with type 2 diabetes: a randomized, double-blind, parallel-group study. Adv Ther. 2015;32(4):306-318.

10. Kurosaki E, Ogasawara H. Ipragliflozin and other sodium-glucose cotransporter-2 (SGLT2) inhibitors in the treatment of type 2 diabetes: preclinical and clinical data. Pharmacol Ther. 2013;139(1):51-59.

11. Inzucchi SE, Matthews DR. Response to Comments on Inzucchi et al. Management of Hyperglycemia in Type 2 Diabetes, 2015: A Patient-Centered Approach. Update to a Position Statement of the American Diabetes Association and the European Association for the Study of Diabetes. Diabetes Care 2015;38:140-149. Diabetes Care. 2015;38(8):e128-129.

12. Kashiwagi A, Isaka H, Taki Y. Long-term safety, tolerability and efficacy of ipragliflozin in combination with and $\alpha$-glucosidase inhibitor in Japanese patients with type 2 diabetes mellitus inadequately controlled with an $\alpha$-glucosidase inhibitor alone-AGLOW Study. Jpn Pharmacol Ther. 2014;42(12):923-939.

13. Kashiwagi A, Isaka H, Kawano H. Long-term safety, tolerability and efficacy of ipragliflozin in combination with a dipeptidyl peptidase-4 inhibitor in Japanese patients with type 2 diabetes mellitus inadequately controlled with a dipeptidyl peptidase-4 inhibitor alone-DAYLIGHT Study. Jpn Pharmacol Ther. 2014;42(12):941-957.

14. Kashiwagi A, Isaka H, Nakahama H. Long-term safety, tolerability and efficacy of ipragliflozin in combination with a nateglinide in Japanese patients with type 2 diabetes mellitus inadequately controlled with nateglinide aloneCANDLE Study. Jpn Pharmacol Ther. 2014;42(12):959975.

15. Iizuka T, Iemitsu $K$, Takihata $M$, Takai $M$, Nakajima $S$, Minami N, Umezawa S, et al. Efficacy and Safety of Ipragliflozin in Japanese Patients With Type 2 Diabetes: Interim Outcome of the ASSIGN-K Study. J Clin Med Res. 2016;8(2):116-125.

16. Schwartz SL, Akinlade B, Klasen S, Kowalski D, Zhang W, Wilpshaar W. Safety, pharmacokinetic, and pharmacodynamic profiles of ipragliflozin (ASP1941), a novel and selective inhibitor of sodium-dependent glucose cotransporter 2 , in patients with type 2 diabetes mellitus. Diabetes Technol Ther. 2011;13(12):1219-1227.

17. Matsuhashi Y, Chikazawa S, Matsui J, Daimon M. Administration of SGLT-2 inhibitor ipragliflozin improves glycemic control and reduces the body weight and fat mass. Progress in Medicine. 2014;34(10):1867-1871. 